\title{
Driving distractions: An insight gained from roadside interviews on their prevalence and factors associated with driver distraction
}

\author{
F. Prat, , M.E. Gras , M. Planes, S. Font-Mayolas, M.J.M. Sullman
}

\begin{abstract}
The present research investigated the proportion of drivers that engage in a wide range of observable and unobservable driving distractions, along with a number of variables associated with driver distraction. A total of 426 semi-structured interviews were performed, with the results weighed according to the proportion of driver licences among city residents of each gender and age group (18-24, 25-44, 45-64, and 65+). Drivers were most inclined to think about phone-related activities when asked about driving distractions, although the vast majority also recognised that a wide variety of other activities can be regarded as distractions. Drivers were aware of the ban on handheld mobile phone activities, but their knowledge of the law was less accurate in relation to other illegal activities, such as manipulating a SatNav while driving. Almost 90\% of participants reported engaging in distractions while driving, such as: looking at something outside the vehicle, thinking about things unrelated to the driving task and manipulating the audio entertainment system. The figures for text messaging, having a handheld or hands-free conversation were also relatively high (43.7\%, 32.2\%, and $25.4 \%$, respectively). Texting while driving was perceived to be the most dangerous secondary activity, followed by having a handheld conversation, with significant differences between distractions. Further, hands-free conversations were perceived to be significantly less risky than handheld conversations. Perceived descriptive norms consistently predicted
\end{abstract}


engagement in all distraction types. The results show that drivers are quite aware that secondary activities can be distracting and are risky, and yet a substantial proportion of drivers reported engaging in a wide variety of distractions while driving.

\section{Keywords}

Descriptive norms, distracted driving, driving distractions, mobile phone, risk perception, 


\section{Introduction}

Driver distractions have been identified as a common causal factor in vehicle collisions by an extensive body of research (e.g. Beanland et al., 2013; Klauer et al., 2006, 2014; McEvoy et al., 2007; Redelmeier \& Tibshirani, 1997; Violanti \& Marshall, 1996). Therefore, measuring their prevalence and their psychosocial correlates are needed to provide information useful for addressing this issue. Although a large body of research has studied engagement in distracted driving using self-report (e.g. Gras et al., 2007; Sullman \& Baas, 2004), direct roadside observations (e.g. Taylor et al., 2007; Townsend, 2006; Young et al., 2010) and instrumented vehicles (e.g. Stutts et al., 2005), a substantial proportion of the research has mainly focused on mobile-phone-related activities. However, the variety of distractions in which drivers engage while driving is much wider. Suffice to say that in the 100-car naturalistic driving study (Klauer et al., 2006), which investigated real-world driving from more than one hundred drivers, more than 40 categories of driving distractions were found by the coders. On the other hand, while observational studies provide a precise estimate of engagement in observable distractions, they do not allow research into their psychosocial correlates. Furthermore, observational surveys do not allow the investigation of internal distractions (e.g., thinking about something or daydreaming), which have also been found to interfere with safe driving (e.g., Martens \& Brouwer, 2013).

Several studies have investigated the prevalence of a wide range of driving distractions using different forms of self-report: online questionnaires (Lansdown, 2012; Young \& Lenné, 2010), telephone interviews (McEvoy et al., 2006a, McEvoy et al., 2006b; Royal, 2003; Schroeder, et al., 2013; Tison et al., 2011), and face-to-face interviews (Fofanova \& Vollrath, 2012; Huemer \& Vollrath, 2011). For instance, Royal (2003) investigated the prevalence of 
several types of driving distractions in two representative samples of more than 4,000 U.S. drivers. The most frequently reported distraction was conversing with passengers; with $81 \%$ of the drivers acknowledging doing so on at least some driving trips. This was followed by changing radio stations or CDs (66\%), eating or drinking (49\%), making outgoing calls on a mobile phone (25\%), taking incoming calls on a mobile phone (26\%) and dealing with children riding in the rear seats (24\%). More recently, two studies conducted using larger U.S. samples have assessed the self-reported frequency of engagement in distracting activities (Schroeder et al., 2013; Tison et al., 2011). Specifically, Schroeder et al. (2013) reported that the most common activities were talking to passengers $(79.5 \%)$, adjusting the car radio (68.4\%), eating and drinking (47.0\%), making and accepting phone calls (39.6\%), and interacting with children in the back seat $(35.5 \%)$.

McEvoy et al. (2006b) studied distracting activities, during the drivers' most recent trip, in a large representative sample from two Australian states. The most commonly reported distractions were lack of concentration (71.8\%), adjusting in-vehicle equipment (68.7\%), looking at people, objects or events happening outside the vehicle $(57.8 \%)$, and talking to passengers (39.8\%). Furthermore, their results showed that, on average, drivers reported engaging in some type of distracting activity every six minutes.

An interview survey conducted by Huemer and Vollrath (2011) provided very detailed information regarding engagement in secondary tasks at the wheel during the last 30 minutes of driving, as well as the duration of these tasks. Strikingly, only $3.8 \%$ of drivers reported not having engaged in any activity other than driving. While the most commonly reported task was the use of integrated devices (58\% of drivers), this only accounted for $5 \%$ of the driving time. In contrast, passenger-related activities were reported by $39 \%$ of the drivers, but this distraction type accounted for $38 \%$ of the time. 
In an online study, Lansdown (2012) also found that the vast majority (91\%) of UK drivers reported using the in-car entertainment system on a daily or weekly basis, while this figure was $81 \%$ for interacting with adult passengers, $51 \%$ for drinking, $46 \%$ for eating, and $34 \%$ for interacting with child passengers. In terms of phone-related distractions, the figure was $32 \%$ for using a hands-free phone, $25 \%$ for reading a text message, $14 \%$ for writing a text, and $14 \%$ for handheld phone use.

While the results from previous studies are difficult to compare, due to differences in their specific goals and methodology, these demonstrate that drivers engage in a broad variety of secondary activities. Furthermore, those that are more commonly tackled by government policies are often not the most prevalent. Knowledge regarding the prevalence of driver distractions has also been created via direct observations in both Spain (Prat et al., 2015b) and abroad (Stutts et al., 2005; Sullman et al., 2015). These studies clearly show that drivers engage in a wide variety of distracting tasks and also that mobile phone use is not the most prevalent distraction. However, as mentioned earlier mobile phone use has been the subject of far more research than any other distraction type and has also been the main focus of efforts aimed at curbing distracted driving (e.g., legislation banning handheld mobile phone use while driving is in 27 of the 28 European Union members). Furthermore, it is also important to identify which activities drivers consider to be distracting, as referring to distractions using general terms may result in drivers taking into account only a small subset of the distractions.

A number of studies have also investigated risk perceptions regarding driving distractions (e.g., Fofanova \& Vollrath, 2012; Huemer \& Vollrath, 2011; Lansdown, 2012; Royal, 2003; Young \& Lenné, 2010; White et al., 2004). The most obvious feature of these studies is that perceptions of risk differ substantially for the different distraction types. Furthermore, several studies have found significant relationships between the frequency of 
engagement and risk perceptions for some specific distractions (e.g. Gras et al., 2007; Hallett et al., 2011, 2012; Prat et al., 2015a; Sullman \& Baas, 2004).

Another important focus of research associated with driver distractions are the psychosocial factors underlying engagement in these tasks. A variety of psychological constructs from different models has been investigated in relation to drivers' secondary task engagement, particularly those considered in Ajzen's (1991) Theory of Planned Behaviour (e.g. attitude, perceived behavioural control and subjective norm; see, for instance, Nemme \& White, 2010, or Walsh et al., 2008). However, perceived descriptive norm (that is, what the respondent thinks others do) has largely been overlooked as a source of social influence (Cialdini, 2007), which has also been the case with distracted driving. Despite this, the behaviour of others can provide influential information about which behaviours are adaptive and effective in a given context and has been found to be a reliable predictor for a variety of behaviours (Cialdini, 2007), including those related to driving (e.g. Carter et al., 2014; Forward, 2009; Palat \& Delhomme, 2012; Waddell \& Wiener, 2014).

To date, no peer reviewed research has comprehensively studied drivers' engagement in a broad range of driving distractions in Spain. Therefore, the present research set out to investigate drivers' engagement in a broad range of driving distractions and to explore a number of variables potentially related to driver distraction, such as risk perceptions and descriptive norms. The research also investigated the relationships these variables had with engagement in driving distractions. Spanish legislation specifically bans the use of handheld mobile phones, navigation systems and other communication devices while driving (BOE, 2009) and punishes such behaviours with a loss of three points on their driving licence. Thus drivers' knowledge of the law regarding distracted driving and the proportion that had been fined for breaking these laws were also investigated. 


\section{Method}

\section{Participants}

The sample consisted of 426 participants ( 205 males, 220 females, 1 unregistered) whose age ranged from 18-78 years old. A minimum sample size of 382 and a quota by sex and age group were targeted, based on the distribution of drivers' licences (operationalised as valid licences) by gender and age (18-24, 25-44, 45-64, and 65+) was initially targeted. This corresponded to a sampling error of $5 \%$ with a confidence level of $95 \%$, although cases exceeding the quotas were retained. Table 1 presents the $n$ by quota, the percentage each quota represents among the total drivers in the reference population and the driving exposure data for each group.

\section{Procedure}

Participants were approached on streets, squares, parks and public facilities in Girona (Catalonia, Spain) from March 2012 to June 2013. They were asked to voluntarily participate in a study on driving behaviour and confidentiality was guaranteed.

The inclusion criteria were: (a) living in Girona, and (b) being a driver. Excluding those who did not met these criteria (467 people were excluded due to their place of residence or not holding a driver's licence), the response rate was $48.6 \%$. The reason given for not participating was also recorded, with $83.9 \%$ of those who did not participate stating a lack of time as the reason. In total, 447 people were interviewed (out of 920 who were approached), although 21 interviews were terminated by the participants before completion (4.7\% of the total interviews).

\section{Instrument}


A semi-structured interview was developed ad hoc for the present research. The interview was preceded by questions to ascertain whether the potential participants met the inclusion criteria. If they met the criteria the interview started with a question about whether they thought drivers engage in activities while driving that could distract them and if so, what these activities were. A free-response format was used to identify which activities they spontaneously identified as driving distractions. The responses that did not fall into any of the previously established categories (presented below) were written down and are presented in the results section. Most of the remaining questions related to the following set of distractions: a) talking on a handheld phone; b) talking on a hands-free phone; c) reading or sending text messages; d) manipulating audio entertainment system; e) manipulating the GPS; f) eating or drinking; g) smoking; h) being absorbed talking with passengers; i) dealing with children or pets; j) looking for, reaching or tiding up an object; k) looking at an object, people or an event outside of the vehicle (hereafter also referred as outside distractions); and 1) being absorbed thinking about things unrelated to driving.

Frequency of engagement was assessed using the item "how frequently do you engage in the following activities while driving?" with three response options (never, sometimes, and often). The two latter response options were collapsed into a single category creating a dichotomous variable (do vs. do not). The perceived descriptive norms variable was assessed using the following item: "among those who are important to you, how many of them engage in the following activities while driving?" with the following response options (nobody, some of them, and most of them). Risk perception was evaluated using the item "in a scale where 0 is not at all likely and 10 is very likely, to what extent do you think it is likely you will crash if you engage in the following activities while driving?".

The last section of the interview focused on legislation and enforcement regarding 
driving distractions. The following questions were asked for all items except for item (1):

"Have you ever been fined for doing any of the following activities while driving?", "do you think it is illegal to do any of the following activities while driving?" and if they thought so, "how many demerit points do you think you can get for talking on a handheld phone [and all remaining distractions] while driving?". Participants were also asked to report their exposure to driving (in terms of both number of days driven per week and kilometres per week), accidents, their age and how old they were when they got their driving licence. The participant's gender was registered by the interviewer.

\section{Statistical analysis}

Statistical analyses were performed using SPSS version 23. Unless otherwise stated, estimates were weighted (the inverse of the probability of being selected if the selection procedure would have been completely random) so that drivers belonging to each quota were weighed the same as the proportion of driver licences among city residents their quota related too.

\section{Results}

\section{What are regarded as driver distractions?}

Table 2 displays the weighted point estimates, standard errors, and 95\% confidence intervals for variables related to the distractions, bans and demerit points for each distraction type. The most spontaneously reported distraction was using a handheld mobile phone with the second being smoking and the third manipulating the audio entertainment system. Apart from handheld phone use, only smoking was spontaneously reported by more than $50 \%$ of those interviewed. Distractions such as talking to passengers, using a hands-free phone, eating 
or drinking, looking at something outside the vehicle and thinking about things unrelated to driving were spontaneously reported by less than one in ten drivers. Aside from the distraction types defined beforehand, participants reported the following additional distractions: reading text or a map $(n=6)$, putting on make-up or grooming $(n=4)$, listening to the radio or music $(n=3)$, writing something on paper $(n=1)$, connecting a portable device $(n=1)$, looking at himself/herself in the mirror $(n=1)$, an insect within the vehicle $(n=1)$, and adjusting mirrors $(\mathrm{n}=1)$.

However, when participants were specifically asked about each distraction almost all of them were deemed to be distractions by at least $90 \%$ of participants. The only exception was for talking with passengers, which was identified as a distraction by $83 \%$ of participants. For distractions such as handheld phone conversations, manipulating the GPS, and external distractions the percentage was near $100 \%$ and all interviewees reported reading a text message to be distracting.

\section{Knowledge of legislation and enforcement}

All drivers were aware of the ban in place for handheld mobile phone conversations and almost all were aware of the ban on text messaging. In contrast, less than $60 \%$ of drivers knew that manipulating a GPS while driving was illegal. Between one fifth and two thirds of drivers thought that eating or drinking, smoking, dealing with children and looking for, reaching or tiding up objects were banned. The weighted percentages of drivers who thought they could lose points from their licence for some of the assessed behaviours were lower than those who thought there was a ban in place for each distraction. As we can see in Table 2, the 95\% CI for these two variables did not overlap for manipulating the audio entertainment system, eating or drinking, smoking, dealing with children, or looking for, reaching or tiding up objects. Furthermore, the chi-square tests assessing the relationship between thinking a 
task was illegal (or not) and whether they entail demerit points were significantly different $(\mathrm{p}<.001)$ for all distraction categories. The unweighted mean number of demerit points participants thought (by at least half the drivers) they could get for engaging in distracting activities they thought were illegal were: $3.19(\mathrm{SD}=1.42)$ for having a handheld conversation, $3.29(\mathrm{SD}=1.52)$ for reading or sending text messages, and $3.15(\mathrm{SD}=1.22)$ for manipulating a GPS.

With regards to fines, only $1.6 \%$ of drivers ( $\mathrm{SE}=.6$; CI 95\%: 0.7-3.3) had received a ticket for handheld phone use and no participant reported fines for any other illegal activities, such as text messaging or manipulating a GPS while driving. One driver reported having been fined for driving through red lights while picking up an object. Despite not having been fined for the distraction itself, such a fine was related to having been distracted.

\section{Descriptive norms}

Table 3 presents the weighted percentages, standard error, and 95\% confidence intervals for each response option and distraction category. Manipulating the audio entertainment system was the distraction which most participants reported that their most important others engage in, with two thirds reporting this. This was followed by thinking about things unrelated to the driving task, looking at something outside the vehicle, and being absorbed talking to passengers. Although only about one in ten drivers reported that the majority of their important ones had handheld mobile phone conversations and manipulate their GPS while at the wheel, more than six in ten said some of these people engage in these activities. A similar pattern (with the greatest proportion of drivers saying that some of their important others engage in them) was found for talking on a hands-free phone, reading or sending text messages, eating or drinking, and looking for, reaching, or tiding up an object. Lastly, "some" was also the most common response for smoking and dealing with children or 
pets, despite the answers being more balanced with respect to the proportion of drivers saying none of their important others engaged in this activity.

\section{Engagement in driving distractions}

Table 4 displays the estimated percentage of drivers who engaged in each distraction measured, along with their standard errors and their $95 \%$ confidence intervals. About $90 \%$ of drivers reported being distracted from the driving task by looking at something outside the vehicle, thinking about things unrelated to the driving task, and manipulating the audio entertainment system, with the last being the most clearly volitional behaviour. Almost $85 \%$ admitted becoming absorbed by talking with passengers while at the wheel. In contrast, GPS manipulation while driving was the least frequently reported task by drivers, with less than $20 \%$ reporting doing so. Around one quarter of drivers reported engaging in smoking and having hands-free phone conversations while driving, while slightly more drivers reported dealing with children or pets. Less than one third of drivers admitted talking on a handheld phone while driving, while over $40 \%$ reported text messaging. Lastly, the majority of drivers reported eating or drinking while driving, as well as moving or placing objects.

In order to evaluate age-related differences in the engagement in each distraction type, chi-square tests were conducted to compare age groups for each gender. For males, significant age differences were found for: using a handheld mobile phone to talk $\left(X^{2}(3)=23.929\right.$; $\mathrm{p}<.001)$, reading or sending text messages $\left(\mathrm{X}^{2}(3)=28.612 ; \mathrm{p}<.001\right)$, manipulating the audio entertainment system $\left(X^{2}(3)=12.139 ; p=.007\right)$, eating or drinking $\left(X^{2}(3)=31.228 ; p=<.001\right)$, smoking $\left(X^{2}(3)=11.722 ; p=.008\right)$, dealing with children or pets $\left(X^{2}(3)=9.167 ; p=.027\right)$; looking for, reaching or tiding up $\left(X^{2}(3)=9.478 ; p=.024\right)$, outside distractions $\left(X^{2}(3)=11.678\right.$; $\mathrm{p}=.009)$ and thinking about things unrelated to the driving task $\left(\mathrm{X}^{2}(3)=20.593 ; \mathrm{p}<.001\right)$. For females, differences were found in: using a handheld mobile phone use to talk $\left(\mathrm{X}^{2}(3)=8.317\right.$; 
$\mathrm{p}=.040)$, reading or sending text messages $\left(\mathrm{X}^{2}(3)=9.099 ; \mathrm{p}=.028\right)$, manipulating the audio entertainment system $\left(X^{2}(3)=21.581 ; p<.001\right)$, smoking $\left(X^{2}(3)=11.895 ; p=.008\right)$, and dealing with children or pets $\left(\mathrm{X}^{2}(3)=13.393 ; \mathrm{p}=.004\right)$.

In almost all cases, where differences were found, younger drivers were more likely to report engaging in the distracting task, except for dealing with children or pets. In this latter category, those drivers (both males and females) aged 18 to 24 were less likely to report engaging in this task, compared to the rest of drivers.

Chi-square tests were also used to test for gender differences by age group for engagement in each distraction type. Male and female drivers aged 18-24 only differed significantly for mobile phone conversations $\left(X^{2}(1)=5.662 ; p=.017\right)$, with the proportion of males being higher (Table 4). For those aged 25-44, gender differences were found for manipulating the GPS while driving $\left(X^{2}(1)=6.403 ; p=.011\right)$, smoking $\left(X^{2}(1)=4.840 ; p=.028\right)$, and dealing with children or pets $\left(\mathrm{X}^{2}(1)=5.726 ; \mathrm{p}=.017\right)$. The proportion of males engaging in the two first distraction types was significantly higher, while the contrary was true for dealing with children and pets. Among those aged 45-64, the proportion of males reporting the manipulation of entertainment systems while driving was significantly higher $\left(X^{2}(1)=6.305\right.$; $\mathrm{p}=.012$ ) than for females. With respect to the older drivers (aged 65+), the proportion of females reporting eating or drinking while driving was significantly higher (Fisher's exact test $\mathrm{p}=.028)$

\section{Perceived crash risk}

Table 5 shows that drivers' perceived crash risk clearly varied by secondary activity. The activity with the highest perceived crash risk was reading or sending text messages, followed by talking on a handheld phone, looking for reaching or tiding up an object, and dealing with children or pets. In contrast, eating or drinking was the secondary task with the 
lowest perceived crash risk, followed by manipulating the audio entertainment system. As shown by the confidence intervals, reading or sending text messages was perceived as more risky than handheld mobile phone conversations, and having handheld conversations was perceived to be more risky than both hands-free conversations and being absorbed talking to passengers. Interestingly, the confidence intervals for hands-free conversations and being absorbed talking to passengers did not overlap. Nonetheless, it should be noted that all paired t-tests for the above comparisons reached statistical significance: handheld phone use vs. hands-free phone use $(\mathrm{t}(423)=22.24 ; \mathrm{p}>.001)$; handheld phone use vs. texting $(\mathrm{t}(423)=-14.31$; $\mathrm{p}<.001)$; handheld phone use vs. talking to passengers $(\mathrm{t}(423)=22.81 ; \mathrm{p}<.001)$; and hands-free phone use vs. talking to passengers $(\mathrm{t}(423)=3.32 ; \mathrm{p}=.001)$.

\section{Predictors of engagement in each distraction type}

Logistic regressions were performed to investigate the relationship between the variables studied in the present research and whether the driver engaged in each distraction type. The demographic and exposure variables were entered in the models using a forced entry method, while the rest of the variables were allowed to enter into the model, providing they made a significant contribution, using the forward Wald method. The additional variables included: spontaneously reporting it as a distraction, considering it to be a distraction, perceived crash risk, descriptive norms, whether they think it is illegal, whether they think they can get demerit points, and having been fined for it.

All models significantly fitted the data, as shown by the chi-square p-values in Table 6 . However, the proportion of variance accounted for by the models differed substantially, with the Nagelkerke's $\mathrm{R}^{2}$ ranging from .153 to .443 . Demographic variables made a significant contribution in a few models, with only age reaching significance in the models for reading or sending text messages and thinking about things unrelated to the driving task. In all of these 
cases increases in age were associated with lower odds of engaging in the secondary activity, while sex was not significant in any of the models. Licence tenure was positively associated with sending or reading text messages and thinking-related distractions. The number of days driven per week was positively associated with having handheld mobile phone conversations while driving, dealing with children or pets, and outside distractions. Likewise, the number of kilometres per week was positively associated with engagement in the following driving distractions: hands-free mobile phone conversations, reading or sending text messages, and manipulating the GPS.

The only variable that was found to be a consistent predictor for every outcome variable was perceived descriptive norm, with the odds ratios associated with this variable ranging from 3.039 (for having handheld conversations) to 19.326 (for thinking about things unrelated to the driving task). In contrast, perceived crash risk was only significant in three models: having a handheld conversation, eating or drinking, and outside distractions. In all cases, the perceived crash risk negatively predicted engagement in the distracting task. Having spontaneously reported the secondary task as a driving distraction was associated with an increase in the odds of being among those who engaged in the following tasks: manipulating the GPS, smoking, dealing with children or pets, and looking or reaching for objects. Furthermore, considering the secondary activity to be distracting significantly reduced the odds of being among those who dealt with children or pets while driving. Thinking that eating and drinking was illegal while driving was associated with an increase in the odds of engaging in this behaviour, while the contrary was true for believing that drivers can get demerit points for engaging in this behaviour.

\section{Discussion}




\section{What tasks are reported to be driver distractions?}

The results regarding spontaneously reported distractions shed further light on what enters a drivers' mind when they think about driving distractions. There is no doubt that handheld phone use is the driving distraction that has been the target of more campaigns communicating its hazardousness and as expected this was spontaneously reported by about $80 \%$ of the drivers. More surprisingly, smoking was reported by more than half of the drivers, despite not having been the focus of much attention by prevention campaigns. However, it is clear that drivers tend to focus mostly on mobile phone use, despite the range of distractions which have detrimental effects on driving being much broader. Conversely, when drivers are asked directly whether these other behaviours are distracting, the vast majority agree. These results must be interpreted in light of the fact that Huemer and Vollrath (2011) found drivers tend to accept that secondary task engagement can be dangerous in general, but a largely reduced proportion accept that they were distracted on specific occasions in which they have engaged in the secondary activities, and even less accept that by engaging in these behaviours they put themselves at risk of crashing.

\section{Knowledge of legislation and enforcement}

Drivers appear to know the law regarding mobile phone use, since the vast majority were aware that handheld mobile phone use (to talk and to text message) is an offence, while one in ten drivers think (wrongly) that hands-free phone use is illegal. Studies in the U.S (Tison et al., 2011; Schroeder et al., 2013) have also found that, in those states with laws banning handheld phone use, an overwhelming majority of drivers were aware of the ban. However, drivers are not so accurate concerning the manipulation of a GPS while driving. Perhaps, the fact that having the GPS functioning while driving is legal (what is illegal is to 
interact with it in a tactile way) contributes to this inaccurate belief and clearly needs to be communicated more clearly. On the other hand, it is somewhat surprising that a substantial proportion of drivers (which ranges from one fifth and to third) think that behaviours such as eating and drinking, smoking and outside distractions are banned, despite not being explicitly illegal in Spain (BOE, 2009). However, the law identifies the drivers' obligations regarding not being distracted, which means that these activities could be illegal if the distraction led to a crash. Furthermore, several news stories appeared some years ago in the media reporting that a driver was fined for eating a croissant (Juanola, 2007), for eating an apple (López, 2008), and for smoking a cigarette (Méndez, 2006), which may have contributed to this misunderstanding. The confusion regarding smoking may be due to the fact that throwing cigarette butts out the window is illegal and that there has recently been debate on prohibiting smoking in cars while carrying children (Laorden, 2012).

It is surprising that a small but substantial proportion of drivers think that some of the distractions are illegal, but being caught while doing so does not entail losing points on their licence. On the other hand, it is worth noting that the average demerit points reported for the three behaviours that are actually punished in this manner was very close to the actual penalty (BOE, 2009).

With regards to reported fines, a very small percentage of drivers reported having been fined for engaging in illegal behaviours, compared to the considerable proportion who reported engaging in these illegal behaviours, suggesting that the enforcement of such laws is low or ineffective.

\section{Descriptive norms}

In general, a substantial proportion of drivers reported that people they consider to be important engage in a wide range of distractions at the wheel. The secondary activity which 
had the highest proportion of drivers that thought none of their important ones engage in was dealing with children or pets. However, even in that case the proportion of drivers who thought that some of their important others engaged in the task far outweighed the proportion who thought their important other did not engage in this activity. Likewise, more than half of drivers thought that some of their important people engaged in distractions such as talking on both handheld and hands-free phones, reading or sending text messages, and manipulating the GPS. Hence, it appears that drivers think distracted driving is pervasive. Taking into account the findings that relate descriptive norms and intentions to use a mobile phone while driving (Waddell \& Wiener, 2014) and also with a composite measure of distracted driving among young novice drivers (Carter et al., 2014), this should be of great concern and further research is needed.

\section{Engagement in driving distractions}

The most commonly reported distracting tasks were: looking at things or events outside the car and thinking about things unrelated to the driving task. It is worth noting that these two behaviours could arguably be defined as non-volitional or at least to be less volitional than other behaviours, such as manipulating the audio entertainment system (third most common). In line with our results, lack of concentration $(71.8 \%)$ and looking outside at people, objects or events $(57.8 \%)$ were also reported as the most common distracting activity which occurred in their last trip (McEvoy et al. 2006b). Manipulating the audio entertainment system, which around $90 \%$ of drivers admitting to doing while driving has also been found to be very common in previous research. For example, Lansdown (2012) found a similar proportion of drivers engaging in in-car entertainment system use on a daily or weekly basis. Royal (2003) found this to be the second most prevalent behaviour in which drivers engage in at least on some trips (66\% of drivers), as also did Schroeder et al. (2013) with $68.4 \%$ of 
drivers reporting doing so at least sometimes. Adjusting the stereo was also the fourth most commonly reported distraction on the drivers' most recent trip (McEvoy et al. 2006b), with $40.1 \%$ of drivers reporting engaging in this activity. As noted by Huemer and Vollrath (2011), it appears that this is among the most commonly reported secondary tasks, despite accounting for a low proportion of the total driving time.

Some $85 \%$ of drivers reported being absorbed by talking with passengers. This finding is in agreement with the finding that $81 \%$ of drivers admitting to do so on at least some trips (Royal 2003) and that $79.5 \%$ of drivers reporting talking with passengers at least sometimes (Schroeder et al. 2013), which in both cases was higher than the proportion reporting using the audio entertainment system. Furthermore, Landsdown (2012) found interacting with adult passengers to be the second most frequently reported distraction with $81 \%$ of drivers reporting they did so on a daily or weekly basis. Talking to passengers was also found to be quite frequently reported by McEvoy et al. (2006b, being the fourth most reported distraction, with $40.5 \%$ of drivers) and passenger-related tasks were the second most frequent distraction type according to research by Huemer and Vollrath's (2011), with 38\% of drivers reporting this. Generally speaking, there is some degree of agreement between the studies, indicating the pervasiveness of passenger-related distractions. This finding is also in agreement with research collected in the same city as the present research using roadside observation (Prat et al., 2015b).

It is also surprising that almost $60 \%$ of drivers reported reaching for objects or placing them while driving. In contrast, Prat et al. (2015b) observed that only $1.1 \%$ were engaged in that activity while driving on urban roads in Girona, while McEvoy et al. (2006b) found that $23.1 \%$ of drivers reported having engaged in this behaviour during their most recent trip. In light of our results and the previous findings, it seems that this is a common activity that 
deserves more attention. On the other hand, just over half of drivers reported that they ate or drank while driving. In line with this finding, Lansdown (2012) found that $51 \%$ and $46 \%$ of participants in their sample reported drinking and eating (respectively) daily or weekly and $49 \%$ reported doing so on at least some trips in the USA (Royal, 2003). Similarly, Schroeder et al. (2013) found $47 \%$ of drivers reported eating and drinking at least sometimes. In contrast, in an observational study Prat et al. (2015b) found only $0.3 \%$ of observed drivers were eating or drinking. Thus, it appears that a great proportion of drivers do so, but rather sporadically.

More than $40 \%$ of drivers reported reading and sending text messages, which was higher than for having handheld (with about a third of drivers) and hands-free conversations (with a quarter of drivers). Observational research conducted in the same city by Prat et al. (2015b) found, however, that the proportion of talking on a handheld phone (1.3\%) was much higher than that of holding a phone in a manner to send a text or to key numbers $(0.4 \%)$. Furthermore, the picture we get from the present study is quite different to that of a study using a sample of university workers in the same city (Gras et al., 2007), since in the earlier study most respondents reported talking, whereas only over a quarter of them reported sending texts messages. However, this may also be related to changes in behaviour, as texting was undoubtedly less common in 2006 than it is today. Furthermore, Gras et al. (2007) found that only $14.3 \%$ of those who had mobile phone conversations while driving used hands-free devices. Although their sampling procedure restricted the age range, the differences are so large that they to point to a change in the engagement in these behaviours, with both the use of text messaging and hands-free devices having increased. Perhaps this change is due to the technological changes that have made texting much cheaper or even free of charge. Lansdown (2012) assessed four phone-related behaviours and found that $32 \%, 25 \%, 13 \%$ and $14 \%$ reported using a hands-free phone, reading a text message, talking on a handheld phone, and 
writing text messages, respectively. Unlike the present research, they found hands-free phone use to be more frequent than its handheld counterpart. A total of $39.6 \%$ of drivers reported accepting or making phone calls at least sometimes in Schroeder et al.'s (2013) study, although this figure is not directly comparable with our results since we computed separate estimates for handheld and hands-free conversations.

The proportion of drivers dealing with children or pets while driving was also high, at 28.1\%. This figure is not dissimilar to that in Lansdown's (2012) research, which found 34\% of drivers reported interacting with passengers on a weekly or daily basis, despite only including child passengers. The same is true for Schroeder et al. (2013) who found that 35.5\% of drivers reported interacting, at least sometimes, with children in the back seat.

The least frequently reported distraction was smoking. Precisely one in four drivers reported smoking while driving. Although that is a relatively small proportion of drivers, it may be that they engage in it for a long period, since this was the second most frequently observed behaviour in the roadside study in Girona, with 3.7\% of drivers being observed smoking (Prat et al., 2015b).

Despite the methodological differences, there is a reasonable degree of agreement between studies regarding what the most prevalent distractions are. Overall, the proportion of drivers engaging in every distraction was high, which suggests that drivers have a varied diet of driving distractions, which needs to be reduced.

\section{Perceived crash risk}

The average perceived crash risk was above the scale midpoint for all distracting tasks. although risk perceptions differed considerably, depending upon the task being assessed, as found in previous research (Lansdown, 2012; Young \& Lenné, 2010; White et al., 2004). Reading or sending text messages was perceived to be the most distracting secondary activity, 
which is consistent with both McEvoy et al. (2006b) and Lansdown (2012) although in the latter study writing and reading text messages were reported separately, with writing being reported to be riskier. Sending text messages was also reported to be the most distracting task in Australian research (Young and Lenné, 2010). Furthermore, research has also found writing text messages to be perceived as being significantly more dangerous than reading a text (Prat et al., 2015a; Young \& Lenné, 2010). Talking on a handheld mobile phone was rated to be the second riskiest distraction, which is also in agreement with Lansdown (2012). Reaching for or tiding up an object and dealing with children or pets were found to be the third and fourth most dangerous activities. In contrast, eating and drinking and manipulating the audio entertainment system were the activities that were perceived to be the least risky. Thus, technological distractions seem to be perceived as being very dangerous, with the exception of adjusting the audio entertainment system.

Interestingly, texting while driving was perceived to be significantly more risky than having a handheld conversation, which is in line with previous findings (McEvoy et al. 2006b; Young and Lenné 2010). Further, handheld conversations were perceived to be more dangerous than hands-free conversations, which also supports previous research (Young \& Lenné, 2010; White et al., 2004). The comparison between having a hands-free conversation and being absorbed by having a conversation with a passenger were not so clear, since their confidence intervals overlapped despite the unweighed comparison showing that hands-free phone conversations were perceived to be more dangerous. Thus, drivers seem to be more aware of the risk of remote conversations than those with passengers. However, it should be noted that the drivers surveyed by Young and Lenné (2010) judged the risks from arguing with a passenger or talking with them to be quite different, which could be interpreted as indicating that they realise the importance of the degree of cognitive and emotional 
involvement.

\section{Predictors of engagement in each distraction type}

The proportion of variance explained varied greatly, depending upon the distracting task. While the model for predicting being absorbed talking to passengers only accounted for $15.3 \%$ of the variance, the percentage was $44.3 \%$ for reading or sending text messages while driving.

Demographic variables contributed to a small number of outcome variables. Specifically, younger drivers were more likely to engage in reading and sending text messages and being distracted by their own thinking. Gender was not a significant contributor to any of the models and licence tenure was only associated with an increase in the odds of reading or sending text messages and being distracted by their own thinking. In contrast, exposure-to-driving variables made contributions in several of the models and in all cases, the more frequently the drivers drove, the more likely they were to engage in the distracting task. Thus, the more days a week people drive, the more often they engage in distractions such as having handheld mobile phone conversations, dealing with children or pets, and outside distractions. Likewise, the higher the number of kilometres per week, the higher the odds of engaging in hands-free mobile phone conversations, reading or sending text messages, and manipulating a GPS.

After controlling for the demographic and exposure-to-driving variables, the most robust predictor of engagement in secondary activities while driving was perceived descriptive norm, which was significant for all distraction types, with a one point increase in this measure at least tripling the odds of being among those who engaged in each distraction type. Previous research has also found descriptive norms to be related to the intentions to engage in mobile phone use while driving (Waddell \& Wiener, 2014), distracted driving 
among young novice drivers (Carter et al., 2014) and other risky driving-related behaviours (Forward, 2009; Moan \& Rise, 2011; Palat \& Delhomme, 2012). Our results appear to support the idea that the perception of others' behaviours can have an influence on one's own behaviour. This raises the possibility of tapping into this construct in order to reduce distracted driving, rather than strictly focusing on threats such as the risk of crashing or even being fined and punished with demerit points. However, these findings should be taken with caution due to the correlational nature of this research. Actually, the fact that this correlation also exists for unobservable behaviours (i.e. thinking about things unrelated to the driving task) may indicate that drivers could simply be assuming that other drivers behave as they do. Thus, this should be a topic for further research.

Perceived crash risk was not predictive of engagement in most of the distraction types that were assessed. The exceptions were handheld mobile phone conversations, eating and drinking, and outside distractions. When predictive, a higher perceived crash risk was related to lower odds of engaging in these distraction types. A similar pattern has also been previously noted by research focusing on mobile phone use (Gras et al., 2007; Hallett et al., 2011, 2012; Sullman \& Baas, 2004).

The significant associations found in some of the models (manipulating the GPS, smoking, dealing with children or pets, and looking or reaching for objects) between having reported each distraction type spontaneously and engaging in these distractions showed that engaging in these distractions (that are not among the most salient for drivers in general) appeared to make these more salient for them.

Drivers who engaged in eating and drinking while driving were more likely to think that these behaviours were illegal. However, thinking that these behaviours were punished with demerit points was associated with a reduction in the odds of engaging in these 
behaviours. This suggests that the threat of losing points from their licence could be more effective than the simple compliance with the law, although more research on this topic is needed to more clearly understand the role of these different aspects.

\subsection{Limitations}

The sample used in this research cannot be considered representative, due to the fact that not all members of the studied population had the same chance of being included in this study, which impedes the generalization of the results. However, quotas by age and gender were used to reduce selection bias and to obtain more accurate results to those sourced from convenience samples (e.g. student samples). Furthermore, using this sampling method we obtained a sample with enough heterogeneity to adequately investigate the relationships between variables. Finally, the results may have been affected by social desirability bias and memory effects since all measures were self-reported.

\subsection{Conclusions}

Most drivers tend to focus on handheld mobile phone conversations when they are asked about distracted driving. However, drivers engage in a wide variety of distractions while driving. Furthermore, most drivers identify secondary activities as distracting and believe that engaging in them increases their crash risk. Drivers' risk perceptions varied widely depending on the specific type of distraction, with mobile phone-related distractions being rated as the riskiest. Interestingly, participants mostly knew about the ban in place for handheld phone-related activities and that they can be punished with demerit points, but knowledge for other distractions were less accurate. Thus, drivers know about the negative consequences that may result from engaging in driving distractions but do so anyway. Finally, this research found descriptive norms to be a consistent predictor of engagement in all types of driving distractions. 


\section{Acknowledgements}

This work was performed whilst the first author was receiving a grant from the University (BR10/13). Likewise, the authors thank C. Ferrussola for her assistance in data collection and data entry. 


\section{References}

Ajzen, I., 1991. The theory of planned behaviour. Organ Behav Hum Decis Process 50, $179-211$

Beanland, V., Fitzharris, M., Young, K.L., Lenné, M.G., 2013. Driver inattention and driver distraction in serious casualty crashes: Data from the Australian National Crash In-depth Study. Accid Anal Prev 54, 99-107.

BOE, 2009. Ley 18/2009, de 23 de noviembre, por la que se modifica el texto articulado de la Ley sobre Tráfico, Circulación de Vehículos a Motor y Seguridad Vial, aprobado por el Real Decreto Legislativo 339/1990, de 2 de marzo, en materia sancionadora. Retrieved 16.07.12, from http://www.boe.es/boe/dias/2009/11/24/pdfs/BOE-A-2009-18732.pdf

Carter, P.M., Bingham, C.R., Zakrajsek, J.S., Shope, J.T., Sayer, T.B., 2014. Social norms and risk perception: Predictors of distracted driving behavior among novice adolescent drivers. J Adolec Health 54, s32-s41.

Cialdini, R.B., 2007. Descriptive social norms as unappreciated sources of social control. Psychometrika 72(2), 263-268.

Fofanova, J., Vollrath, M., 2012. Distraction in older drivers - A face-to-face interview study. Saf Sci 50, 502-509.

Forward, S. E., 2009. The theory of planned behaviour: The role of descriptive norms and past behaviour in the prediction of drivers' intentions to violate. Transp Res Part F Traffic Psychol Behav 12(3), 198-207.

Gras, M.E., Cunill, M., Sullman, M.J.M., Planes, M., Aymerich, M., Font-Mayolas, S., 2007. Mobile phone use while driving in a sample of Spanish University workers. Accid Anal Prev 39, 347-355. 
Hallett, C., Lambert, A., Regan, M.A., 2011. Cell phone conversing while driving in New Zealand: Prevalence, risk perception and legislation. Accid Anal Prev 43, 862869.

Hallett, C., Lambert, A., Regan, M.A., 2012. Text messaging amongst New Zealand drivers: Prevalence and risk perception. Transp Res Part F Traffic Psychol Behav 5, 261-271.

Huemer, A.K., Vollrath, M., 2011. Driver secondary tasks in Germany: Using interviews to estimate prevalence. Accid Anal Prev 43, 1703-1712. doi:10.1016/j.aap.2011.03.029

Juanola, J., 2007, May 8. La multa del croissant [The croissant's fine]. Retrieved from http://www.lavanguardia.com

Klauer, S.G., Dingus,T.A., Neale,V.L., Sudweeks, J.D., Ramsey, D.J., 2006. The Impact of Driver Inattention on Near-crash/crash risk: An Analysis Using the 100car Naturalistic Driving Study Data. (Technical Report No. DOT HS 810 594). National Highway Traffic Safety Administration, Washington DC.

Klauer, S.G., Guo, F., Simons-Morton, B.G., Ouimet, M.C., Lee, S. E. et al., 2014. Distracted driving and risk of road crashes among novice and experienced drivers. N Engl J Med 370, 54-59.

Lansdown, T.C., 2012. Individual differences and propensity to engage with in-vehicle distractions - A self-report survey. Transp Res Part F Traffic Psychol Behav 15, 1-8. Laorden, C., 2012, August 15. Sanidad resucita la idea de prohibir fumar en los coches con menores [Health authorities resurrect the idea of prohibiting smoking in cars carrying minors]. Retrieved from http://www.elpais.com

López, A., 2008, May 24. Multa de tráfico por comer una manzana [Traffic citation for eating an apple]. Retrieved from http://www.lavanguardia.com 
Martens, M.H., Brouwer, R.F.T., 2013. Measuring being lost in thought: An exploratory driving simulator study. Transp Res Part F Traffic Psychol Behav 20, 17-28.

McEvoy, S.P., Stevenson, M.R., Woodward, M., 2006a. Phone use and crashes while driving: a representative survey of drivers in two Australian states. Medical J Aust $185(11 / 12), 630-634$.

McEvoy, S.P., Stevenson, M.R., Woodward, M., 2006b. The impact of driver distraction on road safety: results from a representative survey in two Australian states. Inj Prev 12, 242-247.

McEvoy, S.P., Stevenson, M.R., Woodward, M., 2007. The prevalence of, and factors associated with, serious crashes involving a distracting activity. Accid Anal Prev 39, $475-482$.

Méndez, R., 2006, April 12. Multado con 60 euros un conductor por fumar un cigarrillo al volante [A 60-euro fine for smoking a cigarette at the wheel]. Retrieved from http://www.elpais.com

Moan, I. S., Rise, J., 2011. Predicting intentions not to “drink and drive”' using an extended version of the theory of planned behaviour. Accidt Anal Prev 43, 13781384.

Nemme, .E., White, K.M., 2010. Texting while driving: Psychosocial influences on young people's texting intentions and behaviour. Accid Anal Prev 42, 1257-1265.

Palat, B., Delhomme, P., 2012. What factors can predict why drivers go through yellow traffic lights? An approach based on an extended theory of planned behavior. Saf Sci 50, 408-417.

Prat, F., Gras, M.E., Planes, M., González-Iglesias, B., Sullman, M., 2015a. Psychological predictors of texting while driving among university students. Transp Res Part F Traffic Psychol Behav 34,76-85. 
Prat, F., Planes, M., Gras, M.E., Sullman, M., 2015b. An observational study of driving distractions on urban roads in Spain. Accid Anal Prev 74(8), 8-16.

Redelmeier, D.A., Tibshirani, R.J., 1997. Association between cellular-telephone calls and vehicle collisions. N Engl J Med 336, 453-58.

Royal, D., 2003. Volume I: Findings. National Survey of Distracted and Drowsy Driving. Attitudes and Behavior - 2002 Volume I: Findings. (Report No. DOT HS 809 566). National Highway Traffic Safety Administration, Washington DC.

Schroeder, P., Meyers, M., Kostyniuk, L., 2013. National survey on distracted driving attitudes and behaviors - 2012. (Report No. DOT HS 811 729). Washington, DC: National Highway Traffic Safety Administration.

Sullman, M.J.M. and Baas, P.H., 2004. Mobile phone use amongst New Zealand drivers. Transp Res Part F Traffic Psychol Behav 7, 95-105.

Sullman, M.J.M., Prat, F., Kuzu, D., 2015. A roadside study of observable driving distractions. Traffic Inj Prev 16(6), 552-557.

Stutts, J., Feaganes, J., Reinfurt, D., Rodgman, E., Hamlett, C., Gish, K., Staplin, L., 2005. Driver's exposure to distractions in their natural driving environment. Accid Anal Prev 37, 1093-1101.

Taylor, D.M.D, MacBean, C.E., Das, A., Rosli, R.M., 2007. Handheld mobile telephone use among Melbourne drivers. Med J Aust 187(8), 432-434.

Tison, J., Chaudhary, N., Cosgrove, L., 2011. National phone survey on distracted driving attitudes and behaviors. (Report No. DOT HS 811 555). Washington, DC: National Highway Traffic Safety Administration.

Townsend, M., 2006. Motorists' use of hand held cell phones in New Zealand: An observational study. Accid Anal Prev 38, 748-750.

Violanti, J.M., Marshall, J.R., 1996. Cellular phones and traffic accidents: an 
epidemiological approach. Accid Anal Prev 28, 265-270.

Waddell, L.P., Wiener, K.K.K., 2014. What's driving illegal mobile phone use?

Psychosocial influences on drivers' intentions to use hand-held mobile phones.

Transp Res Part F Traffic Psychol Behav 22, 1-11.

Walsh, S.P., White, K.M., Hyde, M.K., Watson, B., 2008. Dialling and driving: Factors influencing intentions to use a mobile phone while driving. Accid Anal Prev 40, $\underline{\underline{1893-1900 .}}$

White, M.P., Eiser, J.R., Harris, P.R., 2004. Risk perceptions of mobile phone use while driving. Risk Anal 24, 323-334.

Young, K.L., Lenné, M.G., 2010. Driver engagement in distracting activities and the strategies used to minimise risk. Saf Sci 48, 326-332.

Young, K.L., Rudin-Brown, C.M., Lenné, M.G., 2010. Look who’s talking! A roadside survey of drivers' cell phone use. Traffic Inj Prev 11, 555-560. 
Table 1. Participants' characteristics for each quota and estimates for the overall sample.

\begin{tabular}{|c|c|c|c|c|c|c|c|}
\hline & & $n$ & $\begin{array}{c}\% \text { in } \\
\text { population }\end{array}$ & Age & $\begin{array}{l}\text { Licence } \\
\text { tenure }\end{array}$ & Km per week & $\begin{array}{l}\text { Days driven } \\
\text { per week }\end{array}$ \\
\hline & & & & Mean (SD) & Mean (SD) & Mean (SD) & Mean (SD) \\
\hline \multirow[t]{4}{*}{ Males } & $18-24$ & 17 & 4.49 & $22.00(1.84)$ & $3.71(2.09)$ & $104.41(79.21)$ & $3.76(1.95)$ \\
\hline & $25-44$ & 97 & 25.66 & $35.25(5.84)$ & $16.30(6.26)$ & $293.54(428.18)$ & $5.02(1.78)$ \\
\hline & $45-64$ & 62 & 17.08 & $52.58(5.39)$ & $33.52(6.34)$ & $238.79(220.84)$ & $5.02(1.75)$ \\
\hline & $65+$ & 29 & 6.74 & $69.52(3.56)$ & $48.52(4.58)$ & $108.79(93.70)$ & $4.07(2.05)$ \\
\hline \multirow[t]{5}{*}{ Females } & $18-24$ & 28 & 3.71 & $21.68(1.57)$ & $3.18(1.66)$ & 89.11 (105.16) & $2.61(1.57)$ \\
\hline & $25-44$ & 115 & 22.80 & $33.69(5.14)$ & $14.21(5.48)$ & $137.41(112.71)$ & $4.72(2.06)$ \\
\hline & $45-64$ & 63 & 15.74 & $51.10(5.35)$ & $31.31(7.02)$ & $149.68(142.01)$ & $4.21(1.94)$ \\
\hline & $65+$ & 14 & 3.79 & $67.21(2.33)$ & $45.86(4.45)$ & 99.64 (124.46) & $3.07(2.06)$ \\
\hline & & & & $\begin{array}{l}\text { Estimate } \\
\text { (CI 95\%) }\end{array}$ & $\begin{array}{l}\text { Estimate } \\
\text { (CI 95\%) }\end{array}$ & $\begin{array}{c}\text { Estimate (CI } \\
95 \%)\end{array}$ & $\begin{array}{l}\text { Estimate } \\
\text { (CI 95\%) }\end{array}$ \\
\hline Overall $^{\mathrm{a}}$ & & $426^{b}$ & & $\begin{array}{c}42.77 \\
(42.28- \\
43.26)\end{array}$ & $\begin{array}{c}23.35 \\
(22.78- \\
23.91)\end{array}$ & $\begin{array}{c}189.81(164.67- \\
214.95)\end{array}$ & $\begin{array}{c}4.54(4.36- \\
4.72)\end{array}$ \\
\hline
\end{tabular}

${ }^{\mathrm{a}}$ Estimates for the overall sample are computed using weights

${ }^{\mathrm{b}}$ The total does not equal the total sample reported in participants section since gender was not registered for one respondent. 
Table 2. Estimates, standard error, and $95 \%$ confidence intervals for identified distractions and whether they are distractions, illegal and entail demerit points.

Variable Parameter Spontaneously reported Deemed it as Think it is banned Think the as a distraction distracting demerit

\begin{tabular}{|c|c|c|c|c|c|}
\hline \multirow{3}{*}{$\begin{array}{l}\text { talking on a } \\
\text { handheld phone }\end{array}$} & $\%$ & 79.7 & 99.5 & 100 & 10 \\
\hline & SE & 2 & .3 & $\mathrm{a}$ & $\mathrm{a}$ \\
\hline & CI $95 \%$ & $75.5-83.3$ & $98.1-99.9$ & $\mathrm{a}$ & $\mathrm{a}$ \\
\hline \multirow{3}{*}{$\begin{array}{l}\text { talking on a } \\
\text { hands-free phone }\end{array}$} & $\%$ & 5.9 & 87.7 & 12.2 & 1 \\
\hline & SE & 1.2 & 1.6 & 1.6 & 1. \\
\hline & CI $95 \%$ & $4-8.7$ & $84.2-90.5$ & $9.4-15.7$ & $8.3-1$ \\
\hline \multirow{3}{*}{$\begin{array}{l}\text { reading or sending } \\
\text { text messages }\end{array}$} & $\%$ & 20.7 & 100 & 98.4 & 96 \\
\hline & SE & 2 & $\mathrm{a}$ & .6 & .9 \\
\hline & CI 95\% & $17-24.8$ & $\mathrm{a}$ & $96.8-99.2$ & $94-9$ \\
\hline \multirow{3}{*}{$\begin{array}{l}\text { manipulating the } \\
\text { audio } \\
\text { entertainment } \\
\text { system }\end{array}$} & $\%$ & 36.8 & 91.9 & 16.8 & 9. \\
\hline & SE & 2.3 & 1.3 & 1.8 & 1 . \\
\hline & CI 95\% & $32.3-41.6$ & $88.8-94.1$ & $13.6-20.6$ & 7.2 \\
\hline \multirow{3}{*}{$\begin{array}{l}\text { manipulating the } \\
\text { GPS }\end{array}$} & $\%$ & 12.3 & 97.9 & 56.4 & 49 \\
\hline & SE & 1.6 & .7 & 2.4 & 2. \\
\hline & CI $95 \%$ & $9.4-15.9$ & $96-98.9$ & $51.6-61$ & 44.8 \\
\hline \multirow[t]{3}{*}{ eating or drinking } & $\%$ & 8.5 & 92.7 & 29 & 14 \\
\hline & SE & 1.3 & 1.3 & 2.2 & 1. \\
\hline & CI $95 \%$ & $6.2-11.5$ & $89.8-.94 .8$ & $24.8-33.6$ & $11.4-$ \\
\hline \multirow[t]{3}{*}{ smoking } & $\%$ & 50.2 & 94.4 & 24.9 & 13 \\
\hline & SE & 2.4 & 1.1 & 2.1 & 1. \\
\hline & CI 95\% & $45.4-55$ & $91.8-96.2$ & $20.9-29.3$ & 10.4 \\
\hline \multirow{3}{*}{$\begin{array}{l}\text { being absorbed by } \\
\text { talking with } \\
\text { passengers }\end{array}$} & $\%$ & 7.7 & 83 & 2.2 & 1. \\
\hline & SE & 1.3 & 1.8 & .7 & .6 \\
\hline & CI 95\% & $5.5-10.7$ & $79.2-86.3$ & $1.2-4.2$ & $.5-$ \\
\hline \multirow{3}{*}{$\begin{array}{l}\text { dealing with } \\
\text { children or pets }\end{array}$} & $\%$ & 10.3 & 98.5 & 20.2 & 9. \\
\hline & SE & 1.5 & .6 & 2 & 1. \\
\hline & CI 95\% & $7.7-13.6$ & $96.8-99.3$ & $16.6-24.2$ & $7-12$ \\
\hline looking for, & $\%$ & 18.4 & 99.5 & 30.9 & 11 \\
\hline
\end{tabular}




\begin{tabular}{lccccr}
\hline $\begin{array}{l}\text { reaching or tiding } \\
\text { up an object }\end{array}$ & SE & 1.9 & .3 & 2.3 & 1. \\
\cline { 2 - 6 } & CI 95\% & $15-22.4$ & $98.1-99.9$ & $26.6-35.6$ & $8.8-1$ \\
\hline $\begin{array}{l}\text { looking at } \\
\text { something outside } \\
\text { the vehicle }\end{array}$ & $\%$ & 7.3 & 96.6 & 3.4 & .7 \\
\cline { 2 - 6 } & $\mathrm{CI} 95 \%$ & $5.1-10.3$ & $94.4-98$ & $2-5.7$ & $.9-3$ \\
\hline $\begin{array}{l}\text { thinking about } \\
\text { things unrelated to } \\
\text { the driving task }\end{array}$ & SE & 4.8 & 92.6 & $\mathrm{~b}$ & $\mathrm{~b}$ \\
\cline { 2 - 6 } & $\mathrm{CI} 95 \%$ & $3.1-7.4$ & $89.8-94.7$ & $\mathrm{~b}$ & $\mathrm{~b}$ \\
\end{tabular}

${ }^{\mathrm{a}}$ Could not be calculated due to lack of variability.

$\mathrm{b}$ The question was not asked for this item 
Table 3. Estimates, standard error, and 95\% confidence intervals for each category of perceived descriptive norms.

\begin{tabular}{|c|c|c|c|c|c|c|c|c|c|}
\hline & \multicolumn{3}{|c|}{$\begin{array}{l}\text { No important people do } \\
\text { so }\end{array}$} & \multicolumn{3}{|c|}{$\begin{array}{l}\text { Some important people } \\
\text { do so }\end{array}$} & \multicolumn{3}{|c|}{$\begin{array}{c}\text { Most important people } \\
\text { do so }\end{array}$} \\
\hline & $\%$ & SE & CI $95 \%$ & $\%$ & SE & CI $95 \%$ & $\%$ & SE & CI $95 \%$ \\
\hline $\begin{array}{l}\text { Talking on a } \\
\text { handheld phone }\end{array}$ & 23.9 & 2.1 & $20-28.2$ & 63.6 & 2.3 & $58.8-68.1$ & 12.6 & 1.6 & $9.7-16.1$ \\
\hline $\begin{array}{l}\text { Talking on a } \\
\text { hands-free } \\
\text { phone }\end{array}$ & 26.2 & 2.2 & $22.2-30.7$ & 57.2 & 2.4 & $52.3-61.9$ & 16.6 & 1.8 & $13.3-20.4$ \\
\hline $\begin{array}{l}\text { Reading or } \\
\text { sending text } \\
\text { messages }\end{array}$ & 34.6 & 2.3 & $30.2-39.3$ & 51.3 & 2.4 & $46.5-56.1$ & 14.0 & 1.7 & $11.1-17.7$ \\
\hline $\begin{array}{l}\text { Manipulating } \\
\text { the audio } \\
\text { entertainment } \\
\text { system }\end{array}$ & 4.3 & 1.0 & $2.7-6.6$ & 28.8 & 2.2 & $24.7-33.3$ & 67.0 & 2.2 & $62.5-71.2$ \\
\hline $\begin{array}{l}\text { Manipulating } \\
\text { the GPS }\end{array}$ & 28.3 & 2.2 & $24.2-32.8$ & 62.9 & 2.4 & $58.2-67.4$ & 8.7 & 1.4 & $6.3-11.9$ \\
\hline $\begin{array}{l}\text { Eating or } \\
\text { drinking }\end{array}$ & 30.3 & 2.2 & $26.1-34.8$ & 49.8 & 2.5 & $45.0-54.6$ & 19.9 & 2.0 & $16.4-24.1$ \\
\hline Smoking & 39.1 & 2.4 & $34.6-43.8$ & 42.8 & 2.4 & $38.1-47.6$ & 18.1 & 1.9 & $14.8-22.1$ \\
\hline $\begin{array}{l}\text { Being absorbed } \\
\text { talking with } \\
\text { passengers }\end{array}$ & 8.1 & 1.3 & $5.9-11.1$ & 50.2 & 2.5 & $45.4-55.0$ & 41.7 & 2.4 & $37.0-46.4$ \\
\hline $\begin{array}{l}\text { Dealing with } \\
\text { children or pets }\end{array}$ & 41.4 & 2.4 & $36.7-46.2$ & 48.3 & 2.5 & $43.5-53.1$ & 10.4 & 1.5 & 7.8-13.6 \\
\hline $\begin{array}{l}\text { Looking for, } \\
\text { reaching or } \\
\text { tiding up an } \\
\text { object }\end{array}$ & 26.1 & 2.1 & $22.1-30.5$ & 50.7 & 2.5 & $45.9-55.6$ & 23.2 & 2.1 & $19.4-27.5$ \\
\hline $\begin{array}{l}\text { Looking at } \\
\text { something } \\
\text { outside the } \\
\text { vehicle }\end{array}$ & 2.9 & 0.8 & $1.7-4.9$ & 46.5 & 2.4 & $41.8-51.2$ & 50.6 & 2.4 & $45.9-55.3$ \\
\hline $\begin{array}{l}\text { Thinking about } \\
\text { things unrelated } \\
\text { to the driving } \\
\text { task }\end{array}$ & 4.1 & 1.0 & $2.6-6.5$ & 40.7 & 2.4 & $36.1-45.5$ & 55.2 & 2.4 & $50.4-59.9$ \\
\hline
\end{tabular}


Table 4. Estimates, standard error, and 95\% confidence intervals for the engagement in each distraction across each quota group and overall weighed estimation.

Variable Parameter

Males

$\mathrm{Fe}$

\begin{tabular}{lccccccc} 
& & $18-24$ & $24-44$ & $45-64$ & $65+$ & $18-24$ & $24-44$ \\
\hline $\begin{array}{l}\text { Talking on a } \\
\text { handheld phone }\end{array}$ & $\%$ & 64.7 & 40.6 & 32.3 & $\mathrm{a}$ & 28.6 & 37.4 \\
& $\mathrm{SE}$ & 11.9 & 5.0 & 6.0 & $\mathrm{a}$ & 8.6 & 4.5 \\
& $\mathrm{CI} 95 \%$ & $39.7-83.6$ & $31.3-50.7$ & $21.8-44.9$ & $\mathrm{a}$ & $14.8-47.9$ & $29.0-46$. \\
Talking on a & $\%$ & 23.5 & 31.3 & 30.6 & 17.2 & 28.6 & 27.0 \\
hands-free & $\mathrm{SE}$ & 10.6 & 4.7 & 5.9 & 7.1 & 8.6 & 4.1 \\
phone & $\mathrm{CI} 95 \%$ & $8.8-49.4$ & $22.8-41.2$ & $20.4-43.2$ & $7.3-35.7$ & $14.8-47.9$ & $19.6-35$. \\
& $\%$ & 70.6 & 53.7 & 38.7 & 3.4 & 53.6 & 44.7 \\
$\begin{array}{l}\text { Reading or } \\
\text { sending text } \\
\text { messages }\end{array}$ & $\mathrm{SE}$ & 11.3 & 5.1 & 6.2 & 3.4 & 9.5 & 4.7
\end{tabular}

messages

CI 95\% $45.1-87.5 \quad 43.6-63.5 \quad 27.4-51.4 \quad 0.5-21.3 \quad 35.2-71.0 \quad 35.9-54$.

Manipulating

$\%$

94.1

92.7

93.5

72.4

96.4

97.4

SE

2.7

3.1

8.4

3.5

1.5

entertainment

system

Manipulating

CI 95\% 66.7-99.2

85.4-96.5

83.9-97.6

53.4-85.7

78.1-99.5

92.2-99.

$\%$

11.8

30.2

24.2

10.3

7.1

15.7

the GPS

SE

8.0

4.7

5.5

5.7

4.9

3.4

CI 95\% 2.8-37.9

21.8-40.1

15.1-36.4 3.3-28.0

$1.8-24.8$

$10.1-23$

Eating or

$\%$

70.6

63.5

49.2

6.9

53.6

58.3

drinking

SE

11.3

6.4

4.8

9.5

4.6

CI 95\% 45.1-87.5

53.5-72.6

36.9-61.6

$1.7-24.2$

$35.2-71.0$

49.1-66

Smoking

$\%$

47.1

34.4

24.2

6.9

46.4

20.9

SE

12.4

4.9

5.5

4.8

9.5

3.8

CI $95 \% \quad 25.0-70.3 \quad 25.6-44.4$

$15.1-36.4$

$1.7-24.2$

29.0-64.8

14.4-29.

Being absorbed

$\%$

94.1

86.5

85.5

69.0

78.6

87.8

talking with

passengers

SE

5.9

3.5

4.5

8.7

7.8

3.0

CI $95 \%$

Dealing with

$\%$

29.2

19.4

13.8

14.3

45.2

children or pets

SE

4.6

5.0

6.5

6.7

4.6

CI $95 \%$

20.9-39.0

11.3-31.2

5.2-31.9

5.4-32.7

36.4-54.

Looking for, $\%$

82.4

61.5

56.5

37.9

60.7

61.7

reaching or

SE

9.5

5.0

6.3

9.1

9.3

4.5 


\begin{tabular}{|c|c|c|c|c|c|c|c|}
\hline $\begin{array}{l}\text { tiding up an } \\
\text { object }\end{array}$ & CI $95 \%$ & $56.4-94.4$ & $51.3-70.7$ & $43.9-68.2$ & $22.2-56.7$ & $41.8-76.9$ & $52.5-70$ \\
\hline \multirow{3}{*}{$\begin{array}{l}\text { Looking at } \\
\text { something } \\
\text { outside the } \\
\text { vehicle }\end{array}$} & $\%$ & 94.1 & 95.8 & 96.7 & 79.3 & 85.7 & 94.7 \\
\hline & SE & 5.9 & 2.0 & 2.3 & 7.6 & 6.7 & 2.1 \\
\hline & CI $95 \%$ & $66.7-99.2$ & $89.4-98.4$ & $87.7-99.2$ & $60.6-90.5$ & 67.3-94.6 & 88.8-97. \\
\hline \multirow{3}{*}{$\begin{array}{l}\text { Thinking about } \\
\text { things unrelated } \\
\text { to the driving } \\
\text { task }\end{array}$} & $\%$ & $\mathrm{~b}$ & 91.7 & 96.7 & 69.0 & 92.9 & 91.2 \\
\hline & $\mathrm{SE}$ & $\mathrm{b}$ & 2.8 & 2.3 & 8.7 & 4.9 & 2.6 \\
\hline & CI $95 \%$ & $\mathrm{~b}$ & $84.2-95.8$ & $87.7-99.2$ & $50.0-83.2$ & $75.2-98.2$ & 84.4-95. \\
\hline
\end{tabular}

${ }^{\mathrm{a}}$ No participant reported it

${ }^{\mathrm{b}}$ All participants reported it 
Table 5. Mean estimates, standard errors and 95\% confidence intervals for perceived likelihood of having a crash while engaged in each secondary activity.

\begin{tabular}{lccc}
\hline \multicolumn{1}{c}{ Secondary activity } & Mean & SE & CI 95\% \\
\hline Talking on a handheld phone & 7.78 & .067 & $7.65-7.91$ \\
Talking on a hands-free phone & 6.04 & .102 & $5.84-6.24$ \\
Reading or sending text messages & 8.61 & .054 & $8.50-8.72$ \\
Manipulating the audio entertainment system & 5.51 & .084 & $5.35-5.68$ \\
Manipulating the GPS & 6.82 & .074 & $6.67-6.96$ \\
Eating or drinking & 5.31 & .080 & $5.16-5.47$ \\
Smoking & 5.72 & .087 & $5.55-5.89$ \\
Being absorbed talking with passengers & 5.73 & .095 & $5.54-5.92$ \\
Dealing with children or pets & 6.98 & .072 & $6.83-7.12$ \\
Looking for, reaching or tiding up an object & 7.27 & .070 & $7.14-7.41$ \\
Looking at something outside the vehicle & 6.60 & .076 & $6.45-6.75$ \\
Thinking about things unrelated to the driving task & 6.40 & .092 & $6.22-6.58$ \\
\hline
\end{tabular}

Note: scale ranged from 0 (not at all likely) to 10 (very likely). 
Table 6. Logistic regression models predicting the engagement in each distraction type.

\begin{tabular}{|c|c|c|c|c|}
\hline Variable & B & Wald & $\mathrm{p}$ & O.R. \\
\hline \multicolumn{5}{|c|}{ Talking on a handheld phone } \\
\hline Age & -.095 & 3.309 & .069 & .909 \\
\hline Licence tenure & .050 & .926 & .336 & 1.052 \\
\hline Days driven per week & .235 & 12.349 & $<.001$ & 1.265 \\
\hline Km per week & .000 & .158 & .691 & 1.000 \\
\hline Male vs. female & .231 & .858 & .354 & 1.259 \\
\hline Perceived descriptive norm & 1.112 & 24.043 & $<.001$ & 3.039 \\
\hline Perceived crash risk & -.218 & 6.074 & .014 & .804 \\
\hline Chi-squared of the model (p-value) & \multicolumn{4}{|c|}{$89.948(<.001)$} \\
\hline Nalgerke's $\mathrm{R}^{2} ; \%$ correctly classified & \multicolumn{4}{|c|}{$.275 ; 72.7 \%$} \\
\hline \multicolumn{5}{|c|}{ Talking on a hands-free phone } \\
\hline Age & -.047 & .780 & .377 & .954 \\
\hline Licence tenure & .034 & .408 & .523 & 1.034 \\
\hline Days driven per week & -.046 & .401 & .526 & .955 \\
\hline Km per week & .005 & 26.802 & $<.001$ & 1.005 \\
\hline Male vs. female & .116 & .179 & .672 & 1.123 \\
\hline Perceived descriptive norm & 1.442 & 39.300 & $<.001$ & 4.230 \\
\hline Chi-squared of the model (p-value) & \multicolumn{4}{|c|}{$93.328(\mathrm{p}<.001)$} \\
\hline Nagelkerke's $\mathrm{R}^{2} ; \%$ correctly classified & \multicolumn{4}{|c|}{$.302 ; 80.2 \%$} \\
\hline
\end{tabular}

Reading or sending text messages

\begin{tabular}{lcccc} 
Age & -.150 & 7.271 & .007 & .861 \\
Licence tenure & .114 & 4.300 & .038 & 1.121 \\
Days driven per week & .003 & .001 & .970 & 1.003 \\
Km per week & .002 & 4.606 & .032 & 1.002 \\
Male vs. female & -.062 & .057 & .810 & .940 \\
Perceived descriptive norm & 2.170 & 76.611 & $<.001$ & 8.760 \\
Chi-squared of the model (p-value) & \multicolumn{4}{c}{$163.756(<.001)$} \\
Nagelkerke's $\mathrm{R}^{2} ; \%$ correctly classified & \multicolumn{4}{c}{$.443 ; 74.8 \%$} \\
\end{tabular}

Manipulating the audio entertainment system

\begin{tabular}{lcccc} 
Age & -.082 & 3.666 & .056 & .921 \\
Licence tenure & .057 & 1.847 & .174 & 1.058 \\
Days driven per week & .132 & 1.662 & .197 & 1.142 \\
Km per week & .000 & .033 & .857 & 1.000 \\
Male vs. female & .141 & .125 & .723 & 1.151 \\
Perceived descriptive norm & 1.556 & 22.911 & $<.001$ & 4.739 \\
Chi-squared of the model (p-value) & \multicolumn{5}{c}{$56.675(<.001)$} \\
Nagelkerke's R ${ }^{2} ; \%$ correctly classified & \multicolumn{4}{c}{$.277 ; 91 \%$} \\
Manipulating the GPS & -.166 & 3.447 & .063 & .847 \\
Age & .167 & 3.438 & .064 & 1.181 \\
Licence tenure & .074 & .802 & .370 & 1.077 \\
Days driven per week & \multicolumn{3}{c}{}
\end{tabular}


Km per week.

.002

$4.765 \quad .029$

1.002

Male vs. female

.569

$3.712 \quad .054$

1.766

Spontaneously reported distraction

1.113

$9.361 \quad .002$

Perceived descriptive norm

1.310

$21.863<.001$

3.705

Chi-squared of the model (p-value)

$69.569(<.001)$

Nagelkerke's $\mathrm{R}^{2}$; \% correctly classified

$.252 ; 82.7 \%$

\section{Eating or drinking}

Age

$\begin{array}{lll}-.052 & 1.834 & .176\end{array}$

.949

Licence tenure

.031

.633

.426

1.031

Days driven per week

.048

.568

.451

1.049

Km per week

.001

.652

.419

1.001

Male vs. female

$-.159$

.436

.509

.853

Perceived descriptive norm

$\begin{array}{llll}1.212 & 43.401 & <.001 & 3.360\end{array}$

Perceived crash risk

$-.314$

15.556

$<.001$

.731

Think it is illegal

1.213

11.145

.001

3.365

Think they can get demerit points for doing so

$-.927$

$4.041 \quad .044$

.396

Chi-squared of the model (p-value)

$113.538(<.001)$

Nagelkerke's $\mathrm{R}^{2}$; \% correctly classified $.323 ; 69.2 \%$

\section{Smoking}

Age

Licence tenure

$\begin{array}{lll}-.105 & 3.651 \quad .056\end{array}$

.901

Days driven per week

.079

$2.111 \quad .146$

1.083

Km per week

$-.031$

.175

.676

.969

Male vs. female

.000

$.023 \quad .880$

1.000

.490

3.133

.077

1.632

Spontaneously reported distraction

.696

6.588

.010

2.005

Perceived descriptive norm

1.479

$52.775<.001$

4.388

Chi-squared of the model ( $p$-value)

$103.254(<.001)$

Nagelkerke's $\mathrm{R}^{2}$; \% correctly classified

$.328 ; 79.3 \%$

\section{Being absorbed talking with passengers}

Age

$-.031 \quad .615$

.970

Licence tenure

$.021 \quad .284$

.433

1.021

Days driven per week

$\begin{array}{lll}.046 & .343 & .558\end{array}$

1.047

Km per week

$.000 \quad .078$

.780

1.000

Male vs. female

.034

.012

.911

1.034

Perceived descriptive norm

1.308

$28.148<.001$

3.698

Chi-squared of the model ( $p$-value)

$37.765(<.001)$

Nagelkerke's $\mathrm{R}^{2}$; \% correctly classified

$.153 ; 84.6 \%$

Dealing with children or pets

Age

Licence tenure

.023

.300

.584

1.023

Days driven per week

$-.038$

.800

.371

.963

Km per week

.183

6.296

.012

1.201

.000

.008

.930

1.000

Male vs. female

$-.528$

3.569

.059

.590 
Spontaneously reported distraction

$$
\begin{array}{cccc}
1.891 & 18.999 & <.001 & 6.629 \\
-2.048 & 5.228 & .022 & .129 \\
1.572 & 46.625 & <.001 & 4.817 \\
& 127.069(<.001) &
\end{array}
$$

Deemed it as distracting

Chi-squared of the model ( $p$-value)

Nagelkerke's $\mathrm{R}^{2}$; \% correctly classified

$.381 ; 79.8 \%$

Looking for, reaching or tiding up an object

Age

-..066 2.547

.111

.936

Licence tenure

$\begin{array}{lll}.052 & 1.573 \quad .210\end{array}$

1.053

Days driven per week

$\begin{array}{lll}.071 & 1.220 \quad .269\end{array}$

1.074

Km per week

$\begin{array}{lll}.000 \quad .025 & .873\end{array}$

1.000

Male vs. female

$\begin{array}{lll}.123 & .253 \quad .615\end{array}$

1.131

Spontaneously reported distraction

$\begin{array}{lll}.831 & 5.978 \quad .014\end{array}$

2.296

Perceived descriptive norm

1.475

$56.547<.001$

4.372

Chi-squared of the model ( $p$-value)

$107.135(<.001)$

Nagelkerke's $\mathrm{R}^{2}$; \% correctly classified

$.310 ; 73.3 \%$

Looking at something outside the vehicle

Age

$-.086$

2.145

.143

.917

Licence tenure

.085

$2.144 \quad .143$

1.089

Days driven per week

$\begin{array}{lll}.266 & 4.029 & .045\end{array}$

1.305

Km per week

$\begin{array}{lll}-.002 & 1.630 \quad .202\end{array}$

.998

Male vs. female

.349

$.482 \quad .488$

1.417

Perceived descriptive norm

2.436

$20.255<.001$

11.429

Perceived crash risk

$-.609$

$12.100 \quad .001$

.544

Chi-squared of the model (p-value)

$71.754(<.001)$

Nagelkerke's $\mathrm{R}^{2}$; \% correctly classified

$.397 ; 94.5 \%$

Thinking about things unrelated to the driving task

\begin{tabular}{lcccc} 
Age & -.158 & 11.147 & .001 & .854 \\
Licence tenure & .121 & 6.805 & .009 & 1.129 \\
Days driven per week & -.050 & .220 & .639 & .951 \\
Km per week & -.001 & 1.077 & .299 & .999 \\
Male vs. female & .424 & .884 & .347 & 1.528 \\
Perceived descriptive norm & 2.961 & 40.901 & $<.001$ & 19.326 \\
Chi-squared of the model (p-value) & \multicolumn{4}{c}{$88.268(<.001)$} \\
Nagelkerke's $\mathrm{R}^{2} ; \%$ correctly classified & \multicolumn{4}{c}{$.422 ; 92.6 \%$} \\
\hline
\end{tabular}


2017-01-11

\section{Driving distractions: an insight gained from roadside interviews on their prevalence and factors associated with driver distraction}

Sullman, Mark J. M.

Elsevier

F. Prat, M.E. Gras, M. Planes, S. Font-Mayolas, M.J.M. Sullman, Driving distractions: an insight gained from roadside interviews on their prevalence and factors associated with driver distraction, Transportation Research Part F: Traffic Psychology and Behaviour, Volume 45, February 2017, Pages 194-207

http://dx.doi.org/10.1016/j.trf.2016.12.001

Downloaded from Cranfield Library Services E-Repository 